\title{
Questionando histórias únicas: ensino de inglês como língua adicional em uma escola técnica
}

\section{Questioning single stories: English as an additional language teaching at a vocational school}

\author{
Raquel Bevilaqua1 \\ Cândida Martins Pinto²
}

\begin{abstract}
Resumo
Uma história única pode ser definida como uma versão limitante de eventos. Seu poder limitante e hegemônico influencia o modo como o mundo é representado por meio de palavras e imagens, e isso pode influenciar identidades e interações sociais. A autora nigeriana Chimanda Ngozi Adichie (2009) explica que histórias únicas criam e reforçam estereótipos. Portanto, refletir sobre elas a partir de uma perspectiva discursiva deveria ser um dos objetivos da educação linguística ministrada em escolas (GARCEZ, 2008; SCHLATTER, 2009). Neste texto, reportamos uma experiência pedagógica com estudantes de inglês como língua adicional em uma escola profissionalizante, durante a pandemia de Covid-19. A partir da perspectiva da abordagem do Letramento Crítico (JORDÃO, 2013), os(as) estudantes foram encorajados a identificar, analisar e desafiar as histórias únicas reveladas por Adichie (2009) e aquelas as quais eles/elas têm ouvido durante suas vidas. Como resultado, os(as) estudantes produziram histórias curtas sobre várias e diferentes histórias únicas que têm permeado suas diferentes interações sociais. Seus textos foram publicados no formato de um e-book no qual os(as) estudantes compartilham suas reflexões com leitores em geral.
\end{abstract}

Palavras-chave: Ensino de Língua Inglesa. História Única. Letramento Crítico.

\begin{abstract}
A single story can be defined as a limiting version of any events. Its limiting and hegemonic power influences the way the world is represented through words or images, and this may influence people's social interactions and identities. The Nigerian novelist Chimamanda Ngozi Adichie (2009) explains that single stories create and reinforce stereotypes. Therefore, reflecting upon them from a discursive perspective should be one of the aims of linguistic education delivered in schools (GARCEZ, 2008; SCHLATTER; 2009). In this text, we report a pedagogical experience developed with students of English as an additional language at a vocational school during the Covid-19 pandemic. From the perspective of the Critical Literacy approach (JORDÃO, 2013), students were encouraged to identify, analyze and challenge both the single stories presented by Adichie (2009) and the ones they have been told in their lifetime. As a result, students wrote short stories about several and different single stories that have been pervading their different social interactions. Their texts were published in the format of an e-book in which the students share their reflections with readers in general.
\end{abstract}

Keywords: English Language Teaching. Single Story. Critical Literacy.

\footnotetext{
1 Doutora em Letras. Colégio Técnico Industrial de Santa Maria. Santa Maria, RS, Brasil. Orcid: https://orcid.org/0000-00031795-3329 E-mail: raquel@ctism.ufsm.br.

2 Doutora em Letras. Colégio Politécnico da Universidade Federal de Santa Maria. Santa Maria, RS, Brasil. Orcid: https://orcid.org/0000-0003-1587-1127 E-mail: candida.martins.pinto@ufsm.br
}

LínguaTec, Instituto Federal de Educação, Ciência e Tecnologia do Rio Grande do Sul, Bento Gonçalves 


\section{0 uso da língua como prática social enquanto objeto de ensino}

A sala de aula de língua adicional na educação básica deve ser um lócus privilegiado para a aprendizagem e para a prática de usos da língua inglesa em diferentes contextos sociais: na universidade, no cotidiano, no ambiente profissional, entre outros (SCHLATTER, 2009; GARCEZ, 2008). É também o local por excelência em que diferentes discursos encontram-se e podem ser tensionados, questionados, problematizados e (res)significados, cumprindo um dos principais papéis que cabe a este componente curricular, qual seja, formar cidadãs e cidadãos conscientes do lugar que ocupam na sociedade e capazes de decidir se desejam mantê-lo ou transformá-lo (BRASIL, 2006, p. 91).

Com base nesses princípios, objetivamos relatar uma experiência de aprendizagem de inglês como língua adicional em Cursos Técnicos Integrados ao Ensino Médio do Colégio Técnico Industrial de Santa Maria (CTISM), durante a pandemia da Covid-19. Desejamos, alinhadas ao pensamento da professora formadora de professoras(es) de línguas, Margaret Schlatter (2009), que este relato possa inspirar e ajudar outras(os) colegas docentes da educação básica a planejarem atividades pedagógicas a partir de algumas discussões e questões que relatamos neste texto.

A perspectiva de língua que adotamos é a de prática social, constituída por meio de "uma relação bidirecional entre textos e sociedade" (MEURER, 2005, p. 82). Isso significa que a língua tem um potencial constitutivo que não pode ser ignorado: ela constrói formas de ver o mundo, formas de relações entre pessoas e destas com o mundo, e formas de estar no mundo (identidades) (MEURER, 2005). Essas três dimensões do discurso permeiam nossas práticas discursivas e sociais cotidianas e constroem aquilo que vemos e percebemos como 'realidade'. No entanto, uma análise mais atenta ao funcionamento da língua em uso pode mostrar que o que vemos muitas vezes como 'realidade' não passa de um investimento discursivo que nos leva a acreditar que se trata de algo real ou natural.

Um exemplo concreto do uso da língua nessa situação é o caso das notícias falsas sobre a vacina contra a Covid-19. Para algumas pessoas, o acesso a uma notícia falsa, mas com vários elementos linguísticos que a fazem parecer verdadeira (por exemplo: seu layout mimetiza um website de notícias, há uma fonte que diz se tratar do jornal tal, há uma suposta autoria de alguém identificado como "doutor", "especialista" ou "médico", há uso de palavras que constroem credibilidade, como "segundo estudos", "os dados mostram", entre outros) pode ser o suficiente para convencer aquelas pessoas a não se imunizarem, e pior, a convencerem parentes e amigos próximos a fazerem o mesmo.

Partir dessa problemática real (e com efeitos visíveis e concretos sobre a vida social) inscreve este trabalho no campo teórico da Linguística Aplicada contemporânea (KLEIMAN et al., 2019; MOITA 
LOPES, 2006). Kleiman et al. (2019, p. 726), ao revisitarem os propósitos e agenda desse campo de pesquisa, afirmam que, tendo o discurso como elemento central, na Linguística Aplicada, buscam-se

\begin{abstract}
as soluções para melhorar 0 ensino de línguas (embora não exclusivamente), e dessa forma contribuir para a equidade, o empoderamento de comunidades socialmente vulneráveis, a compreensão de estratégias e identidades bem (ou mal) sucedidas, entre outras metas próprias da formação de cidadãos críticos (KLEIMAN et al., 2019, p. 726) (Ênfase adicionada).
\end{abstract}

A formação para a cidadania é uma tarefa que cabe à escola, conforme preconizam documentos de normatização e orientação do currículo escolar, tais como: Lei de Diretrizes e Bases da Educação (BRASIL, 1996), Parâmetros Curriculares Nacionais (BRASIL,1998), Orientações Curriculares para 0 Ensino Médio (BRASIL, 2006) e, mais recentemente, a Base Nacional Comum Curricular (BRASIL, 2018). $O$ exercício da cidadania, conforme esses documentos, é o princípio geral que orienta a educação.

O texto das Orientações Curriculares para o Ensino Médio (BRASIL, 2006), ao explanar os objetivos do ensino da Língua Estrangeira na escola, apresenta uma perspectiva de cidadania que pode ser desenvolvida por meio das aulas de língua adicional, as quais devem envolver:

[...] a compreensão sobre que posição/lugar uma pessoa (o aluno, o cidadão) ocupa na sociedade. Ou seja, de que lugar ele fala na sociedade? Por que essa é a sua posição? Como veio parar ali? Ele quer estar nela? Quer mudá-la? Quer sair dela? Essa posição o inclui ou o exclui de quê? Nessa perspectiva, no que compete ao ensino de idiomas, a disciplina Línguas Estrangeiras pode incluir o desenvolvimento da cidadania (BRASIL, 2006, p. 91) (Ênfase adicionada).

A formação visando à cidadania, nessa perspectiva, vai além do desenvolvimento do capital linguístico apenas, pois objetiva a formação de cidadãos e cidadãs capazes de participarem no mundo de maneira crítica, estando aptos(as) "ao trânsito nas sociedades complexas contemporâneas" (GRACEZ, 2008, p. 52). Portanto, essa formação abrange algo mais amplo do que o capital linguístico, pois envolve o "capital cultural" (GARCEZ, 2008, p. 52).

Nesse sentido, formar cidadãs e cidadãos é também encorajar estudantes a refletirem e problematizarem (questionarem) o mundo tal qual se lhes apresenta, um processo que focaliza e evidencia sua agentividade, isto é, seu potencial ativo de se perceber e se colocar no mundo. Tal postura é mediada inerentemente pela língua enquanto uma prática social e discursiva. Nesse sentido, toda a manifestação da língua põe em funcionamento, de modo simultâneo, os três níveis de significados que seu uso instancia, conforme já mencionamos: "1) formas de conhecimentos e crenças; 2) relações, e 3) identidades" (MEURER, 2005, p. 89). 
Essa concepção crítica da língua em uso, ou do discurso, está diretamente relacionada ao conceito de cidadania, apresentado anteriormente, na medida em que a aprendizagem de uma língua sob essa perspectiva constitutiva do discurso pode criar ou desafiar 1) representações sobre o mundo (como narrativas falsas, por exemplo), 2) formas de relações entre as pessoas (como as assimetrias sociais construídas sob lógicas excludentes e preconceituosas), e 3) identidades, isto é, modos de estar no mundo (como o lugar de onde o sujeito fala ou deseja falar na sociedade).

O ensino e aprendizagem de línguas a partir dessas considerações dá-se pelo viés da abordagem pedagógica do Letramento Crítico (JORDÃO; FOGAÇA, 2012; JORDÃO, 2013). Nessa abordagem, a língua é entendida enquanto discurso, isto é, "espaço de construção de sentidos e representação de sujeitos e do mundo" (JORDÃO, 2013, p. 73). Nesse sentido, a aprendizagem de uma língua adicional deve promover, em última instância, oportunidades para que os atores sociais envolvidos nesse processo possam engajar-se em práticas sociais diversas com um senso crítico mais aguçado que Ihes ajudem a ler o mundo e a agir nele com mais responsabilidade e senso ético. Em uma sociedade global e altamente tecnologizada, na qual notícias falsas e desinformação bem como a proliferação de discursos de ódio, carregados de preconceitos e estereótipos têm se constituído como ameaças à democracia, à saúde pública e às relações de respeito entre as pessoas, aprender a língua inglesa sob a perspectiva que adotamos aqui certamente pode contribuir para a formação de cidadãs e cidadãos mais atentos(as) ao uso da língua em diferentes situações comunicativas.

\section{$2 \mathrm{~A}$ atividade de ensino e seus resultados}

A atividade relatada foi desenvolvida com estudantes de língua inglesa, nível intermediário 1, então cursando o segundo ano de três Cursos Técnicos Integrados ao Ensino Médio do CTISM: Eletrotécnica, Mecânica e Informática para a Internet. Em termos de gênero, 41\% do total de estudantes são meninas e 59\%, meninos. A média de idade é de 16 anos.

Durante o ano letivo de 2020, em função da pandemia da Covid-19, a direção do colégio sugeriu que as aulas e as atividades fossem realizadas preferencialmente por meio da plataforma de código aberto MOODLE 3 e/ou por meio das ferramentas disponibilizadas pelo GoogleSuite (Google Classroom, Google Meet, Google mail; Google Forms, entre outras). As aulas e atividades de língua inglesa foram organizadas para ocorrerem de forma síncrona, uma hora por semana, por meio da plataforma Google

\footnotetext{
3 Sigla em inglês para Modular Object-Oriented Dynamic Learning Environment (Ambiente de Aprendizado Modular Orientado ao Objeto). O MOODLE é uma plataforma online que funciona como uma sala de aula onde professores(as) disponibilizam material didático e propõem tarefas e atividades.
} 
Meet. Os materiais didáticos e atividades assíncronas foram disponibilizados aos(às) estudantes por meio do Google Classroom.

Diferentemente da participação e engajamento dos(as) estudantes nas aulas presenciais, nas aulas promovidas de forma remota, observamos que a taxa de participação discente foi mais baixa, sendo necessário buscar desenvolver atividades diferenciadas que tivessem o potencial de promover um maior engajamento dos(as) estudantes naquele contexto. Nesse sentido, o objetivo da atividade didática, cujas etapas são descritas a seguir, foi o de contribuir para uma educação linguística que, ao mesmo tempo em que poderia promover um maior engajamento dos(as) estudantes no contexto relatado, também estivesse voltada para a cidadania. Com isso em mente, a atividade buscou encorajá-los(as) a refletirem criticamente sobre o poder constitutivo da língua enquanto discurso por meio de análise e produção de histórias curtas sobre uma história única em língua inglesa em nível intermediário.

A primeira etapa no planejamento dessa atividade pedagógica foi a definição de um tema motivador (ou "gerador", nas palavras de FREIRE, 2005, p. 114) a partir do qual outras temáticas de real interesse dos(as) estudantes pudessem somar-se. Em uma perspectiva crítica de ensino de língua adicional, a escolha do tema é uma etapa importante para a proposição das atividades de aprendizagem da língua (TILIO, 2012), seguida da prática de linguagem (ou do gênero discursivo) que se deseja enfocar, juntamente com seus elementos léxico-gramaticais a serem estudados/exercitados pelos(as) estudantes.

Dessa forma, a primeira etapa da atividade partiu de um tema que perpassa a vida de estudantes durante a adolescência de um modo recorrente: estereótipos e seus efeitos sobre as relações sociais e identitárias dos(as) jovens. Esse tema pode ser relacionado a pelo menos dois dos seis temas transversais propostos nos Parâmetros Curriculares Nacionais (BRASIL, 1998): ética e pluralidade cultural. Para abordar o tema, foi escolhida a fala de Chimamanda Adichie, proferida no evento Ted Talk, em 2009, denominada de "O perigo da história única"4. História única, na concepção de Adichie (2009), é entendida aqui como uma categoria conceitual e analítica por meio da qual são construídas representações singulares, limitadas e limitadoras sobre pessoas e sobre o mundo. Nesse sentido, uma história única sobre um grupo de pessoas ou sobre alguma situação social pode construir e/ou reforçar visões de mundo determinadas, como a ainda presente visão de que mulheres seriam naturalmente mais aptas para a área das humanas em contraposição com a das exatas, por exemplo.

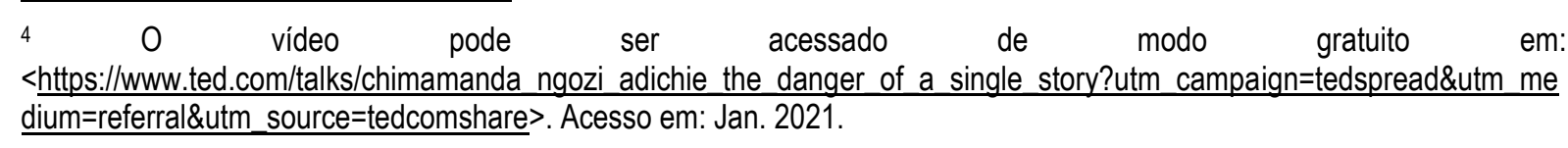


O gênero discursivo aqui denominado de história curta sobre uma história única foi a prática de linguagem enfocada pela atividade. Martin e Rose (2008, p. 53) apresentam uma taxonomia composta de cinco gêneros discursivos (ou textuais, na nomenclatura adotada pelos autores) oriundos da família estórias (ou story): relato, episódio, exemplum, observação e narrativa. Pela taxonomia proposta, o que neste texto denominamos de histórias curtas sobre uma história única produzidas pelos(as) estudantes correspondem ao gênero exemplum, uma vez que seu propósito é "julgar o caráter ou comportamento de uma pessoa" (GERHARDT; FUZER, 2020, p. 754, com base em ROSE, 2014). Nas histórias curtas produzidas, o objetivo foi contar as experiências dos(as) estudantes sobre uma história única e apresentar sua avaliação sobre o caráter limitante/limitador da história. Em razão de a categoria conceitual trabalhada ser denominada de história única, e de a própria Adichie (2009) nomear as histórias que compartilha dessa forma, decidimos manter essa mesma nomenclatura para os textos produzidos pelos(as) estudantes.

Enquanto um gênero discursivo, o propósito comunicativo da história curta sobre uma história única é apresentar uma avaliação sobre um evento narrado. Em sua organização textual, isto é, a macroestrutura, estão os seguintes estágios: 1) Orientação, ou seja, a contextualização da experiência narrada (tempo, lugar e pessoas envolvidas), 2) Complicação, isto é, o evento/acontecimento (que, na atividade proposta, deveria remeter a um exemplo de história única enquanto versão limitante sobre um grupo de pessoas ou evento), e uma 3) Avaliação, estágio em que o(a) narrador(a) expressa sua opinião sobre 0 acontecimento narrado.

Por fim, os aspectos linguísticos abordados, a microestrutura, a partir da temática e do gênero discursivo escolhidos foram os seguintes: 1) tempos verbais no tempo passado; 2) marcadores discursivos de tempo, de modo e de adversidade; e 3) expressões avaliativas (adjetivos e advérbios).

A segunda etapa da atividade consistiu em assistir à fala de Adichie (2009) na plataforma Ted Talk antes do encontro síncrono via Google Meet. O vídeo escolhido contém 18 minutos e 32 segundos, e já obteve mais de 26 milhões de visualizações até o momento de escrita deste texto. Os(as) estudantes poderiam escolher legendas tanto em inglês quanto em português, sendo também possível acessar a transcrição da fala de Adichie na íntegra no próprio website TED. Por ser um vídeo relativamente longo, decidimos propor uma tarefa assíncrona que guiasse a exploração de diferentes partes do vídeo a fim de não só tornar sua visualização mais estimulante, mas também direcionar a atenção dos(as) estudantes a determinadas questões que seriam alvo de discussão no encontro síncrono. As questões norteadoras foram então enviadas aos(às) estudantes via Google Classroom para guiá-los(as) e preparálos(as) para os debates e discussões, e são apresentadas no Quadro 1: 
1. Have you heard about Chimamanda Adichie? Do you know who she is? Where is she from? What does she do for a living? Você já ouviu falar de Chimamanda Adichie? Você sabe quem ela é? De onde ela é? O que ela faz para viver?

2. What did her parents do when she was a child? [2'58" $]^{5}$ O que seus pais fizeram quando ela era uma criança?

3. When she moved to the US, her roommate revealed a single story of Africa. What story was that? [4'12"] Quando ela se mudou para os Estados Unidos, sua colega de quarto revelou uma história única sobre a África. Que história era esta?

4. When Chimamanda Adichie was studying in the US, she traveled to Guadalajara. This trip had an impact on her. What happened in Guadalajara? [8'27"] Quando Chimamanda Adichie estava estudando nos Estados Unidos, ela viajou para Guadalajara. Esta viagem teve um impacto sobre ela. O que aconteceu em Guadalajara?

5. Chimamanda mentions the lgbo word 'nkali'. What does it mean? How is this word related to single stories? [9'36"] Chimamanda menciona a palavra em Igbo 'nkali'. O que ela significa? Qual sua relação com histórias únicas?

Quadro 1: Questões norteadoras.

Fonte: as autoras.

Essas questões foram propostas para orientar os(as) estudantes em relação ao conceito de história única, conforme apresentado por Adichie (2009). Nos momentos demarcados do vídeo, são apresentadas informações sobre Adichie bem como exemplos de histórias únicas que foram a ela contados, sendo um em especial que ela acaba por reconhecer que também reproduziu. A discussão sobre essas questões no encontro síncrono serviu não apenas para compreender o conceito de história única, mas também para estimular os(as) estudantes a buscarem, em suas memórias, outros exemplos que poderiam encaixar-se nesse conceito. Além disso, nesta etapa, os(as) estudantes foram encorajados(as) a refletir sobre algumas questões colocadas a partir de novas histórias únicas levantadas no encontro: 1) Por que as histórias encaixam-se na categoria história única?; 2) Por que a visão apresentada na história é limitante/limitadora?; 3) A história prejudica alguém ou algum grupo de pessoas? Por quê?; 4) Como as pessoas são representadas nessa história?; 5) Que outras versões possíveis podem existir para essa história?; 6) Como é possível desafiar sua visão limitante? Essas questões tiveram o intuito de produzir reflexões sobre o poder constitutivo de uma história única acerca da representação das pessoas e do mundo. Reconhecer esse poder é também uma forma de ser capaz de desafiá-lo e inclusive transformá-lo.

A terceira etapa da atividade consistiu na leitura e análise de um exemplar de história única apresentado por Adichie (2009). A história única sobre os imigrantes mexicanos (aos oito minutos e 12 segundos do vídeo) foi transcrita, lida e analisada no encontro síncrono. A partir desse exemplar, buscouse observar a organização textual do gênero que aqui denominamos de história curta, identificando-se seus três principais estágios, conforme mencionado anteriormente e detalhados no Quadro 2:

\footnotetext{
5 Em razão de ser um vídeo relativamente longo, a marcação do tempo em momentos determinados foi importante para motivar os(as) estudantes a engajarem-se com a tarefa e para fazer referência a determinados trechos da fala durante 0 encontro síncrono.
}

LínguaTec, Instituto Federal de Educação, Ciência e Tecnologia do Rio Grande do Sul, Bento Gonçalves v. 6 , n. 2, p. 193-206, nov. 2021. 


\begin{tabular}{|c|c|c|}
\hline Estágio & escrição & xemplos \\
\hline Orientação & $\begin{array}{l}\text { Lugar: ruas de Guadalajara (México) } \\
\text { Tempo: primeiro dia de uma viagem } \\
\text { a Guadalajara alguns anos atrás; } \\
\text { Pessoas envolvidas: a narradora } \\
\text { (Chimamanda Adichie), mexicanos } \\
\text { como imigrantes (na perspectiva } \\
\text { limitadora dos Estados Unidos) X } \\
\text { mexicanos como comerciantes e } \\
\text { transeuntes }\end{array}$ & $\begin{array}{l}\text { A few years ago, I visited Mexico from the U.S. [...] } \\
\text { There were endless stories of Mexicans as people } \\
\text { who were fleecing the healthcare system, sneaking } \\
\text { across the border, being arrested at the border, that } \\
\text { sort of thing. I remember walking around on my first } \\
\text { day in Guadalajara, watching the people going to } \\
\text { work, rolling up tortillas in the marketplace, smoking, } \\
\text { laughing. I remember first feeling slight surprise. }\end{array}$ \\
\hline $\begin{array}{r}\text { Complicaç } \\
\text { Avalia }\end{array}$ & $\begin{array}{l}\text { Ruptura no fluxo narrativo inicial, } \\
\text { quebra de expectativa, acompanhada } \\
\text { de atitude avaliativa da narradora }\end{array}$ & $\begin{array}{l}\text { And then, I was overwhelmed with shame. I realized } \\
\text { that I had been so immersed in the media coverage of } \\
\text { Mexicans that they had become one thing in my mind, } \\
\text { the abject immigrant. }\end{array}$ \\
\hline Avalia & $\begin{array}{l}\text { Atitude avaliativa da narradora sobre } \\
\text { evento narrado }\end{array}$ & $\begin{array}{l}\text { I had bought into the single story of Mexicans, and I } \\
\text { could not have been more ashamed of myself. }{ }^{8}\end{array}$ \\
\hline
\end{tabular}

Quadro 2: Organização textual de um exemplar da história única sobre imigrantes mexicanos.

Fonte: as autoras a partir de excertos da transcrição da fala de Adichie (2009).

A história única sobre imigração, contada a partir da perspectiva do país que mais recebe imigrantes mexicanos, revela uma visão estereotipada construída (e reforçada pela mídia estadunidense) sobre pessoas do México. Na história única relatada, é possível observar que o uso da língua como uma prática social, discutida na introdução deste texto, põe em funcionamento as três formas simultâneas de construção de significado (MEURER, 2005) e revelam: 1) uma crença ou representação dos mexicanos como uma ameaça aos Estados Unidos (como indicam as escolhas lexicais "roubando", "esgueirandose", "sendo presos"), a qual é ancorada e põe em funcionamento dois tipos de 2) identidades construídas pela história única contada: os mocinhos (pessoas não imigrantes do México que nasceram ou vivem nos Estados Unidos) e os bandidos (imigrantes mexicanos os quais "roubam", "esgueiram-se" e "são presos"). Essa representação e as identidades construídas interferem e impactam nas 3) relações sociais entre não-imigrantes e imigrantes mexicanos, que, por serem construídas sobre uma base dicotômica de nós $X$ eles, é potencializadora de violência (simbólica e até mesmo física).

A narradora dá-se conta de que ela mesma havia "caído na história" única e limitadora sobre as pessoas do México. Quando essa constatação ocorre, a narradora avalia negativamente seu próprio comportamento ("não poderia estar mais envergonhada"), indicando que ela não compactua com essa

\footnotetext{
6 "Alguns anos atrás, visitei o México dos EUA. [...] Havia histórias intermináveis de mexicanos como pessoas que estavam roubando o sistema de saúde, se esgueirando pela fronteira, sendo presas na fronteira, esse tipo de coisa. Lembro-me de andar em meu primeiro dia em Guadalajara, vendo as pessoas indo para o trabalho, enrolando tortilhas no mercado, fumando, rindo. Lembro-me da primeira sensação de ligeira surpresa."

7 "E então, eu fui dominada pela vergonha. Percebi que estava tão imersa na cobertura da mídia sobre os mexicanos que eles se tornaram uma coisa em minha mente, o imigrante abjeto."

8 "Eu havia acreditado na história única dos mexicanos e não poderia ter ficado mais envergonhada de mim mesma."
} 
história (e, logo, não compactua com a representação, identidades e relações sociais instituídas por ela). A avaliação, nesse caso, funciona para identificar e contrapor-se à história única sobre os mexicanos, indicando que seu comportamento (enxergar os mexicanos como imigrantes ameaçadores, como 'inimigos') é censurável.

Feitas as discussões, a análise do texto e de seus aspectos linguísticos (tempos verbais, marcadores discursivos indicando tempo e ruptura de fluxo narrativo - no texto bem como outras opções possíveis, e escolhas lexicais para construir avaliação), passou-se para a quarta etapa da atividade. Nessa etapa, os(as) estudantes receberam a proposta de escrever uma história curta sobre alguma história única que eles desejassem compartilhar. Para tanto, foi esclarecido a eles(as) que os textos produzidos fariam parte de um mural virtual da escola e que a comunidade escolar teria acesso aos textos, ou seja, haveria uma audiência leitora real. Outro aspecto esclarecido foram os objetivos comunicativos dos textos a serem produzidos: contar e desafiar as histórias únicas compartilhadas. Esses esclarecimentos são relevantes para a orientação da produção textual uma vez que, em uma perspectiva de linguagem como uma prática social (MEURER, 2005; JORDÃO, 2013), são fatores que ajudam a contextualizar a prática de escrita e a mobilizar os recursos linguísticos necessários para produzir o texto (GERHARDT; FUZER, 2020).

$\mathrm{Na}$ atividade proposta, trabalhamos com três fases para a produção dos textos escritos: préescrita, escrita e pós-escrita. Na fase de pré-escrita, trabalhada por meio das quatro etapas já mencionadas, houve a preparação para a escrita e os(as) estudantes puderam discutir e refletir sobre histórias únicas por eles(as) conhecidas e escolher uma sobre a qual escrever, além da leitura e análise de exemplares de histórias únicas apresentados por Adichie (2009). Na fase de escrita propriamente dita, ocorreu a produção textual conforme o gênero discursivo previamente analisado. Por fim, a fase de pós-escrita foi constituída pela leitura e feedback da professora a cada texto produzido. O feedback ocorreu na forma de um bilhete orientador ${ }^{9}$ que teve como propósito orientar os(as) estudantes para a reescrita da segunda e final versão do texto. Nesse bilhete, constaram orientações mais gerais acerca do texto produzido (elogio ao tema escolhido como um exemplar de história única, por exemplo), comentários sobre seu atendimento aos três estágios do gênero discursivo trabalhado (como a (in)suficiência de informações contextuais no estágio denominado de Orientação, por exemplo), e orientações mais diretas quanto a aspectos léxico-gramaticais que mereciam ser revistos/corrigidos (como a grafia incorreta de alguma palavra, uso inadequado de determinado tempo verbal, sugestão de

\footnotetext{
${ }^{9} \mathrm{O}$ bilhete orientador é considerado um gênero discursivo por meio do qual o(a) professor(a) interage com o(a) estudante e seu texto, fornecendo feedback para ajudá-lo(a) a qualificar seu texto no processo de reescrita textual. Para mais informações sobre esse relevante instrumento pedagógico, sugerimos a leitura de Fuzer (2012).
} 
uso de determinada palavra ou marcador discursivo, revisão da pontuação, entre outros). Após o feedback, os(as) estudantes produziram a segunda e final versão dos textos, a qual foi avaliada numericamente, fornecendo-lhes parte da média do primeiro trimestre letivo.

A quinta e última etapa da atividade correspondeu à publicização dos textos produzidos e ocorreu após a entrega da versão final das histórias curtas sobre uma história única. Inicialmente, pensou-se em organizar um mural virtual. No entanto, a ideia de transformar os textos em um livreto foi mais bem-recebida pelos(as) estudantes. Para produzir um livreto digital, utilizamos a ferramenta gratuita e online Canva ${ }^{10}$, pois além de oferecer variados recursos textuais e imagéticos, também é possível compartilhar o arquivo produzido no Canva com outras pessoas e inclusive adicioná-las como editoras do arquivo, o que facilitou a produção colaborativa entre estudantes e professora.

O livreto digital11 foi construído na plataforma Canva, e é composto de 13 histórias curtas sobre uma história única escolhida pelos(as) estudantes para serem compartilhadas com leitores(as). Os tópicos escolhidos como representativos do conceito de história única estão descritos no Quadro 3.

\begin{tabular}{|c|c|}
\hline 1. Todo gaúcho toma chimarrão & $\begin{array}{l}\text { 2. A boneca Barbie como modelo para o corpo } \\
\text { feminino }\end{array}$ \\
\hline $\begin{array}{l}\text { 3. Professores são super-humanos acima de } \\
\text { qualquer emoção }\end{array}$ & $\begin{array}{l}\text { 4. O nordeste brasileiro como um lugar de } \\
\text { pobreza e sofrimento }\end{array}$ \\
\hline $\begin{array}{l}\text { 5. Só há uma escola de educação básica da } \\
\text { UFSM na qual se pode estudar }\end{array}$ & 6. Alunos invisibilizados dentro da escola \\
\hline $\begin{array}{l}\text { 7. A visão limitada de cidadãos estadunidenses } \\
\text { sobre a mulher brasileira }\end{array}$ & 8. Pessoas negras e o Rio de Janeiro \\
\hline 9. O Espírito Santo é um estado do nordeste & $\begin{array}{l}\text { 10. Mulheres não têm capacidade para a área das } \\
\text { exatas }\end{array}$ \\
\hline 11. As opções limitadas do refrigerante Fanta & 12. Brasileiros falam espanhol e amam futebol \\
\hline
\end{tabular}

Quadro 3: Tópicos sinalizadores de histórias únicas escolhidos pelos(as) estudantes. Fonte: as autoras.

Os tópicos escolhidos pelos(as) estudantes para produzirem seus textos são bastante diversos e dizem respeito às suas próprias experiências de vida com histórias únicas com as quais tiveram/têm tido contato. Em comum entre eles, há um a apresentação de uma visão limitada (estereotipada) que constitui e perpassa diferentes aspectos sociais: visão limitada de pessoas (gaúchos, cariocas, mulher brasileira, povo brasileiro), de lugares do Brasil (região nordeste e o estado do Espírito Santo), há também referência a questões de gênero (mulher em profissões da área das exatas), a padrões de beleza

${ }^{10}$ Canva é uma plataforma de design gráfico que oferece aos usuários diferentes modelos de design. É uma plataforma gratuita, mas que também oferece outros elementos e recursos em modalidade paga (Canva.com).

11 O livreto pode ser acessado por este link: https://www.ufsm.br/app/uploads/2020/06/Challenging-single-stories_ebook final-version.pdf Acesso em Fev. 2021.

LínguaTec, Instituto Federal de Educação, Ciência e Tecnologia do Rio Grande do Sul, Bento Gonçalves 
socialmente impostos (a boneca Barbie), a questões de classe e de raça (estudantes pobres e negros invisibilizados em uma escola), à questão de poder (professores como seres superpoderosos), e à limitação de escolhas (em relação à escola em que se deseja estudar e em relação ao refrigerante que se deseja beber).

A título de exemplo, apresentamos a Figura 1, que mostra um dos textos produzidos, intitulado "Do they have feelings?" (Eles têm sentimentos?). O texto conta a história única nutrida por muitas crianças sobre seus professores: seres superpoderosos acima de qualquer sentimento. Essa representação é alterada quando, em uma ocasião, a professora não consegue conter as lágrimas diante de uma situação estressante com seus alunos. O narrador dá-se conta da vulnerabilidade de sua professora, o que acaba por humanizá-la para ele. A Figura 1 também mostra os três estágios do gênero discursivo trabalhado em sala de aula:

When I was a child, I studied at a school called "Ceduca". It was really
nice, I had a lot of friends and I played with them all the time. At that time,
I believed that there were two types of people in schools: the teachers and
the schoolchildren. Maybe for being a child, I used to see teachers as a
different kind of humans. To me, they were like super-humans, who were
above all kids. And, at Ceduca, there was a teacher that everyone liked,
because she had a good relationship with all the kids.
However, one day, she made something wrong, so my classmates and
I began to mistreat her. I can't remember the motive, but we were really
angry. Maybe it was just because we were pampered children. Anyway,
with all the confusion in the classroom, suddenly, she began to cry. I had
never seen a teacher crying before. She told us that she should not be
doing that, but just could not hold her sadness. So, that was how I bought
the single story of the teachers. And that was how I discovered that, even
being forced to hide them, teachers do have feelings.

When I was a child, I studied at a school called "Ceduca". It was really I believed that there were two types of people in schools: the teachers and the schoolchildren. Maybe for being a child, I used to see teachers as a different kind of humans. To me, they were llke super humans, who were ove ecause she had a good relationship with all the kids.

However, one day, she made something wrong, so my classmates and I began to mistreat her. I can t remember the motive, but we were really angry. Maybe it was just because we were pampered children. Anyway, with all the confusion in the classroom, suddenly, she began to cry. I had doing that, but just could not hold her sadness. So, that was how I bought being forced to hide them, teachers do have feelings.

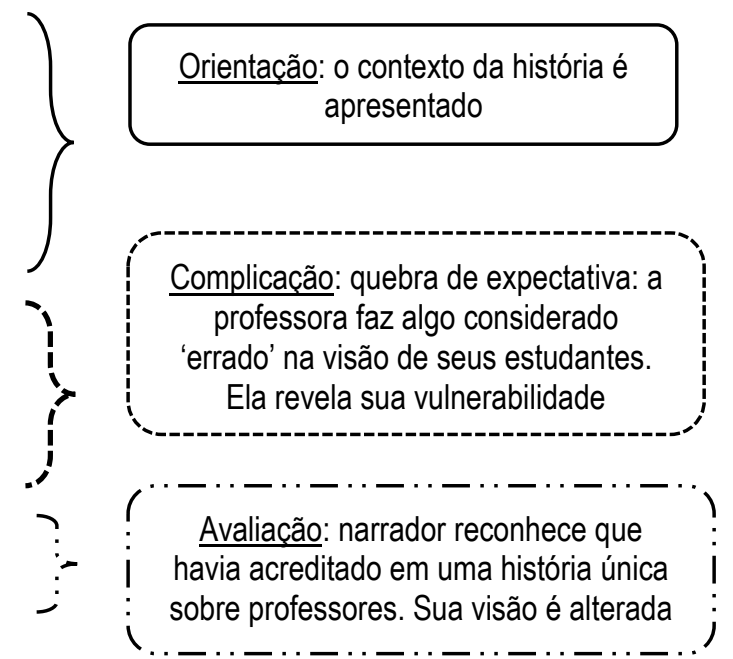

Figura 1. Exemplo de uma história curta sobre história única produzida por um estudante Fonte: As autoras com base no texto do estudante Bruno Camargo Machado ${ }^{12}$.

\footnotetext{
12 Tradução livre: "Quando eu era uma criança, eu estudei em uma escola chamada "CEDUCA". Era muito boa, eu tinha muitos amigos e brincava com eles o tempo todo. Naquele tempo, eu acreditava que havia dois tipos de pessoas em escolas: os professores e as crianças da escola. Talvez por ser uma criança, eu costumava ver professores como um tipo diferente de humanos. Para mim, eles eram como super-humanos, que estavam acima de todas as crianças. E, no CEDUCA, havia uma professora que todo mundo gostava porque ela tinha um bom relacionamento com todas as crianças. No entanto, um dia, ela fez algo errado, então meus colegas e eu começamos a destratá-la. Eu não consigo lembrar o motivo, mas nós estávamos muito bravos. Talvez fosse apenas porque éramos crianças mimadas. De qualquer forma, com toda a confusão na sala de aula, de repente, ela começou a chorar. Eu nunca tinha visto uma professora chorando antes. Ela nos disse que não deveria estar fazendo aquilo, mas não conseguia conter sua tristeza. Então, assim foi como acreditei na história única dos professores. E assim foi como descobri que, mesmo sendo forçados a escondê-los, professores realmente têm sentimentos."
} 
Outras histórias como esta revelam crenças e representações que são desafiadas pelos(as) autores(as) dos textos. As histórias curtas sobre uma história única compartilhadas pelos(as) estudantes incitam reflexões diversas sobre diferentes questões que têm perpassado suas vivências. Por meio de atividades como esta, a aprendizagem da língua inglesa é acompanhada do desenvolvimento da consciência crítica e, portanto, tem o potencial de contribuir para a formação da cidadania plena.

\section{Considerações finais}

Neste texto, relatamos uma atividade pedagógica de ensino de inglês para estudantes de turmas de segundos anos de cursos técnicos integrados ao ensino médio do CTISM. Para esse relato, buscamos apresentar as fundamentações teórico-metodológicas que embasaram nossas escolhas e procedimentos didáticos. A primeira delas é a concepção de língua/linguagem como discurso (JORDÃO, 2013) e como uma prática social (MEURER, 2005), a qual revela o poder constitutivo da linguagem na construção e manutenção ou mudança de determinadas visões de mundo. Essa concepção, conforme buscamos demonstrar, está profundamente associada ao conceito de cidadania plena apresentada em diferentes documentos reguladores e diretivos das práticas de educação no Brasil.

Metodologicamente, ancoradas na concepção de língua/linguagem que adotamos, tentamos mostrar que o desenvolvimento da atividade relatada enseja uma prática pedagógica sustentada no diálogo, em sua concepção mais ampla (FREIRE, 2005), o qual tem o potencial de subverter uma lógica pedagógica tradicional ao dar mais voz aos(às) estudantes. Além disso, a atividade buscou fomentar a aprendizagem da língua adicional de modo a ampliar o capital linguístico em língua inglesa em nível intermediário dos(as) estudantes a fim de que possam melhor compreender e produzir textos nesta língua.

Sob o viés do Letramento Crítico (JORDÃO; FOGAÇA, 2012; JORDÃO, 2013), buscamos também desenvolver e ampliar o capital cultural dos(as) estudantes ao encorajá-los(as) a analisar criticamente narrativas que criam e/ou reforçam histórias únicas, e que comprometem a formação e o exercício de uma cidadania plena.

Por fim, buscamos dar visibilidade às reflexões realizadas pelos(as) estudantes para a comunidade acadêmica do CTISM (e talvez de outras escolas de Santa Maria) ao divulgar os textos produzidos na forma de um livreto digital. 


\section{Referências}

ADICHIE, C. N. The danger of a single story. TED: Ideas worth spreading, New York, 2009. Disponível em:

$<$ https://www.ted.com/talks/chimamanda_adichie_the_danger_of_a_single_story/transcript?language=p t\#-631368>. Acesso em: 20 Jan. 2021.

BRASIL. Ministério da Educação. Base Nacional Comum Curricular. Brasília, 2018.

BRASIL. MEC/Secretaria de Educação Básica. Orientações curriculares para o ensino médio. Brasília: Ministério da Educação, Secretaria de Educação Básica, 2006. V. 1: Linguagens, códigos e suas tecnologias.

BRASIL. MEC/Secretaria de Estado de Fazenda. Parâmetros Curriculares Nacionais: terceiro e quarto ciclos do ensino fundamental: língua estrangeira. Brasília: Ministério da Educação, Secretaria de Estado de Fazenda, 1998.

BRASIL. Lei de Diretrizes e Bases da Educação Nacional, LDB. 9394/1996.

FREIRE, P. Pedagogia do oprimido. Rio de Janeiro: Paz e Terra, 2005.

FUZER, C. Bilhete orientador como instrumento de interação no processo ensino-aprendizagem de produção textual. Letras, Santa Maria, v. 22, n. 44, p. 213-245, 2012. Disponível em: <https://periodicos.ufsm.br/letras/article/view/12198>. Acesso em: 23 jul. 2020.

GARCEZ, P. Educação linguística como conceito para a formação de profissionais de Língua Estrangeira. In: L. MASELLO (org.). Portugués lengua Segunda y extranjera em Uruguay: Actas del Primeiro Encontro de Português Língua Estrangeira do Uruguai. Montevidéu, Faculdad de Humanidades y Ciencias de la Educación/Comisión Sectorial de Investigación Científica, 2008, p. 51-57.

GERHARDT, C. C.; FUZER, C. Toda estória é uma narrativa? Gêneros de texto exemplum e episódio em livro didático de língua portuguesa. Trab. Ling. Aplic., Campinas, n (59.1), p. 746-776, 2020. https://doi.org/10.1590/010318135912020565321

JORDÃO, C. M. Abordagem comunicativa, pedagogia crítica e letramento crítico - farinhas do mesmo saco? Em: HILSDORF, C. R.; FRANCO, R. M. (Orgs.) Língua Estrangeira e Formação Cidadã: por entre discursos e práticas. Campinas, SP: Pontes Editores, 2013, p. 69-90.

JORDÃO, C. M.; FOGAÇA, F. Critical literacy in English language classroom. D.E.L.T.A., v. 28, n.1, p. 69-84, 2012. https://doi.org/10.1590/S0102-44502012000100004

KLEIMAN, A.; VIANNA, C. D.; DE GRANDE, P. A Linguística Aplicada na contemporaneidade: uma narrativa de continuidades na transformação. Calidoscópio, v. 17, n. 4, 2019. https://doi.org/10.4013/cld.2019.174.04

MARTIN, D.; ROSE, D. Genre Relations: Mapping Culture. London: Equinox, 2008.

MEURER, J.L. Gêneros textuais na análise crítica de Fairclough. IN: MEURER, J.L.; BONINI, A.; MOTTAROTH, D. (Org.). Gêneros: teorias, métodos, debates. São Paulo: Parábola, 2005. pp. 81-106. 
MOITA-LOPES, L.P. (org.). Por uma Linguística Aplicada indisciplinar. São Paulo, Parábola Editorial, 2006.

SCHLATTER, M. O ensino de língua estrangeira na escola: uma proposta de letramento. Calidoscópio, v. 7, n. 1, p. 11-23, 2009. https://doi.org/10.4013/cld.2009.71.02

TILIO, R. Atividades de leitura em livros didáticos de inglês: PCN, letramento crítico e panorama atual. Revista Brasileira de Linguística Aplicada, v. 12, n. 4, p. 997-1024, 2012. https://doi.org/10.1590/S1984$\underline{63982012000400016}$

Data de submissão: 23/03/2021. Data de aprovação: 03/11/2021. 